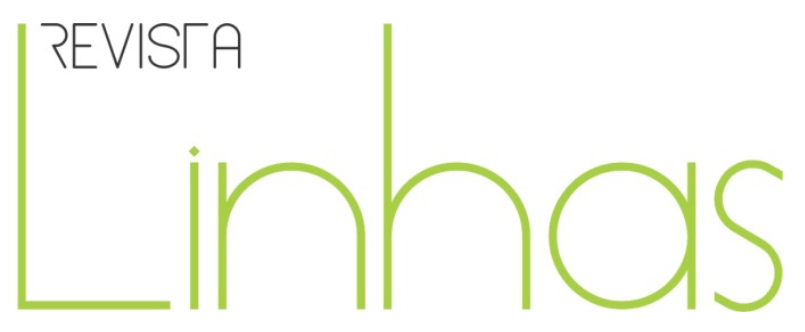

\title{
Jogos em sala de aula e seus benefícios para a aprendizagem da matemática ${ }^{1}$
}

\begin{abstract}
Resumo
Este artigo tem como objetivo avaliar, com base em estudos da literatura especializada e em reflexões sobre práticas de sala de aula, os benefícios da utilização de jogos como material didático para o ensino de matemática. Analisa também a sua influência na resolução de problemas pedagógicos, como a indisciplina, a apatia, os obstáculos para a inclusão e a necessidade de superação da aprendizagem mecânica da matemática. São apresentados os resultados de uma pesquisa sobre a ocorrência de jogos em aulas de matemática. Nas atividades pedagógicas avaliadas, foram utilizados dois jogos: o jogo Contig e o jogo da onça e dos cachorros. Os resultados da utilização destes dois jogos são analisados, bem como as reações de alguns alunos que vivenciaram esta experiência.
\end{abstract}

Palavras-chave: Jogos; Aprendizagem; Matemática.

\section{Ricardo Roberto Plaza Teixeira}

Doutor em Ciências pela Universidade de São Paulo - USP rrpteixeira@bol.com.br

\section{Katia Regina dos Santos da Apresentação Graduanda em Licenciatura em Matemática no Instituto Federal de São Paulo - IFSP krsapresentacao@hotmail.com}

\section{Para citar este artigo:}

TEIXEIRA, Ricardo Roberto Plaza; APRESENTAÇÃO, Katia Regina dos Santos da. Jogos em sala de aula e seus benefícios para a aprendizagem da matemática. Revista Linhas, Florianópolis, v. 15, n. 28, p. 302-323, jan./jun. 2014.

\section{DOI: $10.5965 / 1984723815282014302$}

http://dx.doi.org/10.5965/1984723815282014302

\footnotetext{
${ }^{1}$ Agradecemos ao CNPq pela bolsa de iniciação científica PIBIC concedida à aluna Katia Regina dos Santos da Apresentação.
} 


\title{
Games in the classroom and its benefits for the learning of mathematics
}

\begin{abstract}
This article aims to evaluate, based on studies from the literature and reflections about classroom practices, the benefits of using games to teach mathematics. It also examines its influence in solving problems such as indiscipline, apathy, barriers to inclusion and the need to overcome rote learning of mathematics. It is presented the results of a survey about the occurrence of games in mathematics lessons. In the educational activities proposed, two games were used: the Contig game and the game of the jaguar and the dogs. The results of using these two games are analyzed, as well as the reactions of some students who experienced it.
\end{abstract}

Keywords: Games; Learning; Mathematics. 
Segundo Borin (1996), o uso dos jogos nas aulas de matemática é um importante fator que contribui para diminuir os bloqueios apresentados por muitos alunos que temem a matemática e sentem-se incapacitados de aprendê-la. A literatura sobre questões relacionadas ao ensino e à aprendizagem deixa claro que sem um agente motivador, dificilmente o aprendiz se torna disponível para o processo educativo, ocorrendo apenas uma aprendizagem mecânica e não uma aprendizagem significativa. Para Ausubel, Novak e Hanesian (1980), só ocorre aprendizagem receptiva significativa quando a tarefa ou o conteúdo a ser aprendido se torna significativo durante o seu processo de internalização e passa a fazer sentido para o educando. O principal desafio de todo professor está então na questão de como tornar significativa a aprendizagem dos conteúdos de sua disciplina.

Por meio da utilização de jogos, o aluno constrói seu conhecimento de maneira ativa e dinâmica e os sujeitos envolvidos estão geralmente mais propícios à ajuda mútua e à análise dos erros e dos acertos, proporcionando uma reflexão em profundidade sobre os conceitos que estão sendo discutidos. Isto proporciona ao professor condições de analisar e de compreender o desenvolvimento do raciocínio do aluno e de dinamizar a relação entre ensino e aprendizagem, por meio de reflexões sobre as jogadas realizadas pelos jogadores.

O jogo pode colaborar com a educação matemática e com a educação científica em geral, pois ajuda a resolver situações problemas e desenvolve habilidades de raciocínio lógico e espacial, de concentração, de interpretação, de investigação, de previsão, de análise por comparação e de tomada de decisão lógica e embasada em fatos e argumentos. O jogo aproxima deste modo o educando do conhecimento científico, pois ele passa a viver virtualmente situações de busca por soluções de problemas próximos daqueles enfrentados pelos cientistas durante o processo de construção do conhecimento científico (MOURA, 1994). Ao entender e internalizar as regras de um jogo, o aluno se habilita para entender as regras do grande jogo da natureza a qual todos nós pertencemos: as leis científicas (NOVELLO, 2005). As habilidades desenvolvidas pela 
utilização de jogos na educação são necessárias para o desenvolvimento científico integral dos cidadãos, sem o qual nenhum país pode aspirar progressos sociais e econômicos significativos, pois o aluno condicionado a somente reproduzir mecanicamente conceitos, tende a perder a motivação para aprender e, consequentemente, a população em geral tende a perder a capacidade de discernimento efetivo sobre temas científicos e tecnológicos, algo que é fundamental para o fortalecimento da cidadania. Assim, não há como contrapor a educação científica com a educação para a cidadania: um cidadão só é realmente consciente, autônomo, solidário e participativo na medida em que compreende e compartilha do conhecimento científico produzido pela humanidade.

A utilização do jogo como material pedagógico tem como objetivo criar um ambiente descontraído que viabilize a aprendizagem significativa por meio da observação, da criatividade, do pensamento lógico, da resolução de situação problema, da articulação com diferentes conhecimentos e da inter-relação com os colegas de sala. $O$ jogo desenvolve o senso de autonomia, pois cada um é, em última análise, responsável pelas suas próprias jogadas: como é sempre mais gratificante encontrar as soluções para determinadas situações por si mesmo (ZASLAVSKY, 2000), o jogo em si acaba por adquirir um caráter de fruição que encanta e motiva aqueles que dele participam. O desenvolvimento do aprendizado com a utilização de jogos é interdisciplinar, uma vez que todas essas capacidades desenvolvidas são necessárias para um bom desempenho em outras atividades e em diferentes disciplinas, sejam elas escolares ou não. Despertar o interesse do aluno pela matemática por meio da utilização de jogos, por exemplo, contribui para que esta disciplina deixe de priorizar unicamente aspectos formais e abstratos, tornar-se mais dinâmica e, também, divertida, pois somente problemas abordados de forma desafiadora criam um ambiente de disposição para a busca de soluções (ZASLAVSKY, 2009). Porém, o professor deve planejar sua ação com o objetivo de o jogo não se tornar um mero lazer. Ter regras claras e ser previamente experimentada é uma maneira de garantir o sucesso da atividade como meio de aprendizagem; assim sendo o professor pode utilizar diferentes tipos de jogos, mas, evidentemente, não de qualquer jeito (MACEDO, 2000). Finalmente, é fundamental 
perceber que o jogo deve estar inserido de modo harmônico na totalidade do projeto educacional a ser realizado (KISHIMOTO, 1996).

\section{As diferentes formas de como trabalhar com jogos em sala de aula}

Os jogos, na área da educação, podem ser classificados de muitas maneiras: por modalidades, por faixa etária, por grau de dificuldade, etc. Para as finalidades deste trabalho os jogos são classificados em três categorias (BRENELLI, 1996) - jogos estratégicos, jogos de treinamento e jogos geométricos - mas há situações em que alguns jogos têm características que pertencem a mais de uma destas categorias.

Jogos estratégicos desenvolvem habilidades relacionadas ao raciocínio lógico. Nestes jogos, apropriando-se das regras, o educando busca caminhos para atingir o objetivo final, utilizando-se estratégias e prevendo jogadas do seu adversário, antecipando-se a elas. Esta classe de jogos exige um maior estudo de cada movimento e um pensamento lógico apurado, porque a sorte geralmente não costuma interferir nos resultados destes jogos. Alguns exemplos conhecidos de jogos de estratégia são: xadrez, resta um e damas.

Para substituir as "listas de exercícios" frequentemente pouco eficientes em termos educacionais, são utilizados os jogos de treinamento que são úteis como um reforço para conteúdos anteriormente estudados pelos alunos. Estes também podem ser denominados de jogos de fixação de conteúdos ou jogos de reforço. Alguns exemplos de jogos de treinamento são: bingo da tabuada e jogos de tabuleiros com cartas de perguntas e respostas.

Tangram, Tetris ${ }^{\circledR}$, origami e cubo mágico são alguns dos exemplos mais conhecidos de jogos geométricos. Estes têm como objetivo desenvolver a percepção de espaço e a observação sistematizada das formas geométricas, além do raciocínio dedutivo e da imaginação. São utilizados para a construção de conhecimentos e tópicos relacionados à geometria e à visão espacial, tais como figuras geométricas, semelhanças entre figuras, ângulos e polígonos. 
Para trabalhar com jogos, o professor tem que considerar alguns pontos e características importantes: objetivo, público, material, tempo, espaço, dinâmica, papel do adulto, proximidade de conteúdo, avaliação e continuidade (MACEDO, 2000).

O primeiro ponto a ser analisado pelo professor que pretende utilizar-se de algum jogo em sala de aula é avaliar o objetivo que se quer atingir com a sua utilização. Ele serve para direcionar e atribuir significado para a atividade com o jogo, estabelecendo eventuais conexões com outras áreas de conhecimento. Conhecer a cultura, a estrutura social, a idade e os interesses do público ao qual as atividades se destinam, é uma condição imprescindível para a escolha correta da atividade, pois permite prever o tempo de concentração exigida e o grau de conhecimento necessário dentro de cada faixa de desenvolvimento dos estudantes. Após definidos o objetivo e o público, deve-se analisar o material necessário para a atividade, que precisa estar adequada à realidade; é necessário levar em conta a possibilidade de reposição do material que possa eventualmente ser estragado ou perdido. Avaliar o tempo e o espaço necessário para a realização da atividade com os jogos, evita confusões que possam tumultuar o desenrolar do trabalho. Qualquer jogo requer um tempo para ser desenvolvido e aplicado de maneira satisfatória, por isso a sua utilização deve ser avaliada e programada previamente, em termos espaciais e temporais. Apresentar um jogo novo com alguns minutos para acabar a aula, seguramente não produzirá um bom resultado. Considerar o espaço necessário, a organização dos móveis e a limpeza do ambiente, faz parte do planejamento preliminar que é importante para o sucesso da atividade com jogo em sala de aula.

É fundamental estudar a dinâmica do jogo, prever as possíveis dúvidas que podem aparecer no decorrer das atividades e planejar as estratégias que irão compor as ações dos jogadores, desde as instruções até a finalização. Quando ocorre um elemento surpresa, desencadeando outra dinâmica, é importante antes de esquivar-se, considerálo, observando se é razoável aproveitá-lo para discussões juntamente com os alunos. Para isso, as finalidades da atividade devem ser muito bem definidas pelo professor durante o seu planejamento. 
O papel do educador, após as instruções, será determinado pela dinâmica adotada no planejamento, podendo ele assumir o papel de jogador, de juiz, de observador ou simplesmente ficar circulando pela sala, criando situações problemas, elaborando mecanismos capazes de suscitar questões úteis e adequadas aos alunos e desencadeando reflexões e descobertas. Seu papel será melhor definido pela proposta da atividade. É importante que o educador relacione o jogo a conteúdos específicos de uma disciplina ou a habilidades necessárias para o processo de educação até para que a sua utilização não seja considerada um "tempo perdido" pela comunidade escolar. Neste quesito, o professor deve se aproveitar do duplo papel (SMOLE, 2008) que o jogo tem em sala de aula - como material pedagógico (formador) e como lazer (lúdico) - para motivar e potencializar o uso desta ferramenta.

A avaliação da proposta de uma atividade didática que use um jogo é feita a partir dos objetivos iniciais, se estes estão sendo alcançados e se é necessário melhorar alguns aspectos da abordagem. Na situação de jogo, o educando não se sente avaliado - como ocorre em um exame ou em uma prova - tornando-se acessível ao educador e, muitas vezes, possibilitando a verbalização e a possível superação dos obstáculos epistemológicos com que ele se depara no processo de aprendizagem. Outro aspecto a ser considerado no trabalho educacional com jogos é o caráter do erro que deixa de ter um papel negativo no processo de aprendizagem, tornando-se um aliado do professor na construção de conhecimentos. A análise do erro e do acerto pelo aluno se dá de maneira natural proporcionando a reflexão e a recriação de conceitos matemáticos que estão sendo discutidos; o professor tem condições de analisar e compreender o desenvolvimento do raciocínio do aluno e de dinamizar o processo de aprendizagem, por meio de questionamentos sobre as jogadas realizadas pelos jogadores, evitando assim, que ocorra uma aprendizagem puramente mecânica de conceitos abstratos e artificiais, como acontece, muitas vezes, com as tradicionais listas de exercícios. Uma má jogada constitui uma excelente oportunidade de intervenção do professor, para analisar o erro de maneira positiva, utilizando-o como fonte de construção de novas hipóteses (PINTO, 2000). 
É importante manter uma continuidade em um projeto de utilização de jogos, para que se possa avaliar a sequência de atividades, as necessidades do público, os objetivos futuros a atingir e o desenvolvimento dos alunos no que se refere às habilidades e aos conhecimentos envolvidos. Eventuais problemas que apareçam durante a implementação das atividades com o jogo como estratégia pedagógica, não podem ser encarados como fracassos, mas sim como parte do caminho a percorrer, algo que acontece também no transcorrer dos próprios jogos e no transcorrer dos complexos processos de pesquisa científica e tecnológica. O processo de desenvolvimento e de mudança de nível do aprendiz de um determinado jogo, durante todo o seu transcorrer, acontece geralmente em quatro etapas: a) exploração do material e aprendizagem das regras; b) prática do jogo e construção de estratégias; c) resolução de situações problemas; d) análise das implicações do jogar. Não há uma receita pronta, como facilmente pode-se perceber, porém vários tipos de atividades educacionais com jogos existentes na literatura especializada, podem em tese ser adaptadas para diversas situações escolares.

\section{A utilização de jogos nas aulas de matemática}

A utilização de jogos como método de ensino não é uma proposta recente. Platão já defendia os efeitos positivos da utilização de jogos nos processos educativos: a própria dialética não deixa de ser uma espécie de jogo lógico (GRANDO, 2000). Piaget (1978) também refletiu a respeito da importância da utilização de jogos simbólicos para a construção da inteligência pelas crianças. As atividades lúdicas em geral, como no caso das brincadeiras e dos jogos, são fundamentais para o desenvolvimento cognitivo e intelectual (KAMII e DEVRIES, 1991). O desenvolvimento da psicologia no século XX permitiu pensar o aluno como sujeito que também é responsável pela construção de seu próprio conhecimento, deixando ele de ser um mero consumidor de aulas: com esta visão, o jogo torna-se uma ferramenta preciosa para o processo de aprendizagem.

O uso de jogos como materiais pedagógicos se desenvolveu no Brasil, sobretudo a partir da década de 1980, mas mesmo com o intenso apoio do Ministério da Educação 
(MEC) e dos Parâmetros Curriculares Nacionais (PCN's) de Matemática (BRASIL, 1997), a partir dos anos 90, os jogos ainda são pouco usados em sala de aula.

Para a fundamentação do estudo aqui apresentado inicialmente foi feita uma extensa pesquisa bibliográfica para verificar as características de diferentes propostas de utilização dos jogos como recurso pedagógico, tanto na atualidade quanto em outras épocas da história da educação. A revisão bibliográfica realizada serviu como embasamento teórico de todo o processo investigativo.

A pesquisa de campo envolveu uma diversidade de procedimentos metodológicos (questionários, entrevistas, observações) de modo a conseguir avaliar os efeitos do trabalho pedagógico com jogos na prática docente. A principal ação investigativa para coletar dados e informações a este respeito, foi a realização de uma pesquisa quantitativa com 224 alunos do segundo ciclo do Ensino Fundamental em três escolas públicas nos municípios de Ubatuba e Caraguatatuba (ver tabela 1), situados no litoral norte do estado de São Paulo. Esta amostra foi composta de 45,1\% de meninas e de 54,9\% de meninos. Eles responderam a um questionário curto com o objetivo de avaliar a ocorrência de jogos em aulas de matemática, bem como o ponto de vista dos alunos a respeito deste uso. Assim sendo as duas principais perguntas feitas aos alunos no questionário foram: 1) se eles gostavam ou não de jogos; 2) se eles já tinham usado um jogo em alguma aula de matemática. Procuramos compilar os resultados das duas perguntas na tabela de dupla entrada apresentada abaixo (Tabela 1). Ela mostra que cerca de $81 \%$ dos alunos (181 alunos) afirmaram gostar de atividades com jogos em sala de aula, mas apenas $11 \%$ deles (25 alunos) afirmaram já ter utilizado jogos nas aulas de matemática, o que confirma que a utilização de jogos como recurso pedagógico ainda é pouco explorada.

\begin{tabular}{|l|c|c|c|}
\hline \multicolumn{4}{|c|}{ utilização de jogos em aula de matemática } \\
\hline & sim, já usou & não usou & TOTAL \\
\hline gosta de jogos & 21 & 160 & 181 \\
\hline não gosta de jogos & 4 & 39 & 43 \\
\hline total & 25 & 199 & 224 \\
\hline
\end{tabular}

Tabela 1 - Pesquisa realizada com 224 alunos do segundo ciclo do ensino fundamental de três escolas públicas dos municípios de Caraguatatuba e Ubatuba. 
Apesar de haver uma ampla literatura a respeito, o uso dos jogos no ensino de matemática ainda não se tornou uma realidade concreta e disseminada em sala de aula, mesmo com a existência de materiais acessíveis que englobam desde softwares até jogos de baixo custo e que podem até ser desenhados no chão e jogados com pedrinhas.

Entrevistas semiestruturadas, realizadas pelos autores com professores de matemática das três escolas públicas do litoral norte do estado de São Paulo que contribuíram com o processo investigativo, apontaram como principal motivo da não utilização de jogos em sala de aula, a questão da gestão de sala. A utilização de jogos no ambiente escolar produz geralmente um excesso de ruído, às vezes atrapalhando o trabalho das salas adjacentes e também dificultando o início da aula seguinte, pois os alunos se agitam muito com a atividade, tomando tempo para aquietá-los para a próxima aula, mas isto, de certa forma, também vale para as aulas de educação física, por exemplo. Outro motivo para a resistência à utilização de jogos é o tempo necessário para desenvolver a atividade de maneira satisfatória, que muitas vezes não se encaixa com o tempo didático que o professor tem para desenvolver determinados conteúdos.

O barulho em sala de aula frequentemente é inevitável, pois é exatamente por meio de discussões sobre as jogadas que é possível refletir sobre os resultados e melhorar o desempenho. Mas o sucesso da atividade não é imediato: o professor deve ter muita paciência para colher os frutos desse trabalho e isso realmente requer tempo. $O$ professor deve também estar consciente que tanto situações previsíveis, quanto situações imprevistas poderão ocorrer em sala com seus alunos: é importante poder aproveitá-las da melhor maneira, explorando inteligentemente as novas possibilidades do jogo, de modo a estimular a autonomia, a criatividade, a responsabilidade e a cooperação entre os participantes, habilidades estas necessárias para além de sala de aula (MARCO, 2004). Neste processo o professor também se torna aprendiz (FREIRE, 1997) e tem a oportunidade de vivenciar um processo de aprendizagem ativa, juntamente com o aluno.

Após recolher os questionários e sistematizar os dados obtidos a partir deles, os autores prepararam um plano de uma aula experimental de matemática utilizando jogos. Este plano foi elaborado para contemplar na sua execução atividades matemáticas a partir dos dois jogos escolhidos, o Contig e o Jogo da onça e dos cachorros. Oito 
encontros foram realizados no decorrer de dois meses envolvendo três grupos de alunos diferentes, desse modo somando 24 experimentos didáticos com jogos em sala de aula. Neste período foram gravadas algumas entrevistas com os alunos envolvidos (utilizandose de perguntas simples para motivar o entrevistado a externar os seus pontos de vista) e no fim de cada encontro os autores analisaram os acontecimentos registrando suas conclusões e observações em um diário de campo que forneceu desta forma um riquíssimo material de análise para todo o processo educativo realizado.

\section{Resultados das atividades realizadas com jogos}

Este trabalho foi direcionado para a prática em sala de aula, de modo a averiguar o processo, as dificuldades e as soluções que permitam viabilizar a utilização de jogos como um recurso pedagógico efetivo na área da matemática. As atividades, descritas e analisadas abaixo, foram realizadas com três grupos diferentes de estudantes e com encontros semanais em horário de contra turno, nas aulas de recuperação dos alunos do $9^{\circ}$ ano durante $\mathrm{o}$ ano de $2011 \mathrm{em}$ uma escola estadual de Caraguatatuba. Os educandos envolvidos tinham idade variando entre 13 e 15 anos. Observou-se o aumento de frequência a esta atividade no decorrer dos encontros: inicialmente os grupos eram de 6 alunos e, no final, a média era de cerca de 20 alunos por grupo, o que é um indicador da boa receptividade das atividades com os alunos. As atividades acabaram por contar também com a participação ativa de alunos que não estavam incluídos no programa de reforço escolar. Após selecionar, confeccionar e testar os dois jogos que serão o foco deste trabalho - o jogo da Onça e dos Cachorros (Anexo 1) e o jogo Contig (Anexo 2) estes jogos foram apresentados aos alunos. $\mathrm{O}$ jogo da Onça e dos Cachorros foi escolhido como primeira opção em todos os grupos. Isto porque, segundo os alunos, no tabuleiro do jogo Contig existiam muitos números e, portanto, ele deveria ser mais difícil, na opinião deles. Este pode ser um indício de uma resistência ao trabalho com números ("numerofobia") e aos possíveis cálculos deles decorrentes, uma vez que os alunos ainda não conheciam as regras de nenhum dos dois jogos, quando fizeram a sua primeira opção. 
O jogo da Onça e dos Cachorros é classificado como um jogo de estratégia e no Brasil é considerado um jogo com origem indígena (GRANDO, 2010), mas há evidências de que outras culturas usaram jogos análogos a este. Os adversários têm de analisar as jogadas com estratégias diferentes: o movimento da onça é semelhante aos movimentos realizados no jogo de damas para "capturar" cachorros, mas os movimentos dos cachorros devem ser analisados como um trabalho em equipe, para que eles possam conseguir cercar a onça. Os alunos mostraram grande dificuldade em ganhar utilizando no tabuleiro as peças referentes aos cachorros. Talvez por estarem acostumados a jogar damas, ganhavam geralmente apenas quando estavam jogando com a peça referente à onça. Frequentemente perdiam o interesse pelo jogo, devido à dificuldade em criar estratégias para ganhar utilizando as peças que representam os cachorros. Além disso, o jogador que representa os cachorros deve ter total atenção ao jogo, pois um descuido pode significar a perda de um cachorro. Como crianças e adolescentes são, com frequência, excessivamente distraídos, perdem peças com facilidade quando estão jogando com as peças dos cachorros, pois são vítimas de estratégias oportunistas do jogador que representa a onça. Este jogo da onça possibilita discussões interessantes sobre geometria, pois o tabuleiro é formado por um quadrado e um triângulo: há uma simetria especular, mas ao contrário dos tabuleiros quadrados como o do xadrez, não há simetria de rotação por um ângulo de $90^{\circ}$. A inserção do triângulo cria um espaço que pode ser perigoso para encurralar a onça, portanto as estratégias de ambos os lados têm que levar em consideração a geometria do tabuleiro. A própria elaboração do tabuleiro (desenhado no papel ou até mesmo no chão de terra) é um momento interessante para o ensino de conteúdos da geometria. Além disto, à "assimetria” do tabuleiro, soma-se a assimetria entre os jogadores que têm um número de peças iniciais diferentes com movimentos possíveis diferentes e diferentes objetivos a atingir. Questões relacionadas ao conceito de simetria foram importantes no desenvolvimento histórico da matemática e da física; do mesmo modo questões sobre a sua existência ou não neste jogo, podem colaborar para a aprendizagem de conceitos matemáticos importantes.

A segunda opção que foi apresentada aos alunos, o jogo Contig (GRANDO, 2000), pode ser classificado como um jogo de estratégia e também de treinamento, pois exige a 
execução de cálculos mentais, mas ao mesmo tempo requer um raciocínio estratégico para conseguir ganhar por pontuação ou mesmo fechar o jogo com o alinhamento de cinco peças. Durante as atividades, nas primeiras rodadas, geralmente os alunos ocuparam os números menores do tabuleiro, buscando as operações mais simples, como é o caso da soma. Nas demais rodadas, observou-se uma maior desenvoltura nas jogadas, participação, envolvimento e nas situações do jogo. As atividades com o jogo Contig constituíram uma fonte interessante de análise para a pesquisa de campo e confirmaram alguns pontos já enfatizados pela fundamentação teórica do uso pedagógico dos jogos em geral. Os alunos geralmente utilizam-se muito mais da adição e da multiplicação do que da subtração ou da divisão. Além disso, em certas situações, o uso dos parênteses é necessário para que seja obtida uma determinada resposta: este é um bom momento para discutir o seu papel na matemática e de que modo a ordem das operações influencia nos resultados.

A utilização destes dois jogos nas aulas integrou os alunos em um ambiente harmônico; participaram das atividades alunos com dificuldade de comportamento e de aprendizado. Entre os depoimentos coletados durante as atividades se faz necessário destacar o depoimento de um aluno "repetente", que estava nas aulas de reforço de matemática e que afirmava odiar matemática:

Matemática é muito chata. (...) Sei lá, na sala com aquele giz com a lousa, enche o saco. Aqui é mais legal, você tá competindo, a gente dá risada, a gente brinca. (...) Quem dera, se as aulas de matemática fossem assim, com joguinho. Aprender fórmula de Baskhara com joguinho, teorema de Pitágoras com joguinho...

Outro aluno, que também não tinha um bom desempenho nas aulas tradicionais, mostrou grande contentamento pelas atividades com o jogo Contig, causando admiração e espanto em seus colegas de sala, que não o julgavam capaz de realizar operações matemáticas com tamanha desenvoltura. Uma aluna que tinha muita dificuldade de aprendizagem mostrou interesse imediato pelo jogo logo no primeiro dia de atividade, mas não conseguiu jogar no início, pois foi rejeitada como parceira de jogo pelos colegas da sala e não aceitou a aproximação dos profissionais envolvidos na atividade. Buscando informações junto à coordenadora da escola, descobriu-se que a aluna em questão tinha 
problemas de relacionamento com adultos e que ter demonstrado interesse pelo jogo já era um grande avanço, uma vez que esta geralmente ficava apática nas atividades de sala. No segundo dia de atividade, procurou-se estreitar a relação com esta aluna antes do início das atividades previstas para a aula, quando ela ainda estava no pátio. A abordagem foi bem sucedida, criando um vínculo de amizade. Em sala, outro colega que apresentava dificuldades operatórias, aceitou jogar com ela: para ambos, o envolvimento com o jogo significou uma superação pessoal de grandes barreiras. Isto confirma que o jogo serve também como ferramenta útil para provocar a interação e para a inclusão.

Por meio de resolução de situações problemas envolvendo o jogo Contig foi possível conduzir a atividade para abordar conteúdos de aritmética com grande facilidade de compreensão e com a participação dos alunos, devido às próprias regras e à dinâmica deste jogo. Foram trabalhadas, inclusive, algumas noções pré-algébricas, pois algumas das situações-problema que surgiam, envolviam quantidades desconhecidas que deveriam ser determinadas. É o caso do seguinte questionamento, feito aos alunos para que estes tentassem descobrir a resposta para um enigma envolvendo uma variável desconhecida: "Se em dois dados tem-se os valores 3 e 6 e o jogador ocupou no tabuleiro a casa de número 33, que número poderia estar no $3^{\circ}$ dado?”.

Particularmente, o problema apresentado no Anexo 3, foi trabalhado com os alunos com resultados positivos, em termos didáticos. O contexto da situação proposta no tabuleiro levou muitos alunos a desenvolverem estratégias matemáticas para resolver a contento o desafio proposto. Por exemplo, se a conclusão para este desafio for a de que 35 é o melhor número para a próxima rodada (pois apresenta mais casas adjacentes ocupadas por peças), pode-se perguntar ao aluno sobre qual é a maneira possível para obter um resultado igual a 35 com os valores de três dados e duas operações aritméticas. Assim, por exemplo, pode-se obter 35 por meio de $6 \times 5+5$ e também por meio de $6 \times 6-1$. As análises das jogadas que foram sistematizadas individualmente, quando colocadas na lousa (de maneira a manter o sigilo dos seus autores, os dono das anotações), geraram grandes discussões relacionadas à matemática e à utilização correta da sua linguagem, proporcionando uma ótima oportunidade de intervenção para o educador que por meio de perguntas criou condições para que os educandos encontrassem as respostas. Os 
alunos também não se sentiram constrangidos em mostrar suas ideias e o raciocínio operatório realizado, não se sentindo avaliados. Esta experiência confirmou que podemos afirmar que o jogo é um bom instrumento, inclusive, para a avaliação, uma vez que foge das normas tradicionais pelas quais o aluno tem medo de externar o erro, o que por sua vez, desencadeia um obstáculo para a aprendizagem, pois o educador não consegue compreender o erro que é cometido pelo aluno.

Ruídos de grande intensidade e que podem incomodar costumam acompanhar este tipo de atividade, o que é um problema que pode ser contornado utilizando-se de estratégias corretas. O jogo perderia o seu teor lúdico se os alunos fossem submetidos à lei do silêncio, pois o processo pedagógico está justamente no ato de trocar e externar ideias e dúvidas. As atividades foram realizadas no refeitório da escola, com um resultado satisfatório para a resolução do problema relativo ao barulho.

As atividades foram aprovadas pela coordenadora da escola estadual onde este trabalho foi feito e que acompanhou toda a sua evolução. A seu pedido, alguns resultados da pesquisa foram apresentados aos professores da escola em uma reunião, o que gerou uma rica troca de experiências e tornou-se um agente motivador para a realização de novas atividades.

\section{Considerações finais}

A utilização do jogo como material pedagógico não faz milagres em sala de aula devemos desconfiar de soluções milagrosas na educação - tampouco é a solução para todos os problemas de aprendizagem de conteúdos e de atitudes, porém pode-se afirmar pelas práticas vivenciadas nesta pesquisa que o jogo pode ser uma ferramenta valiosa em sala de aula. O trabalho pedagógico com jogos executado durante o transcorrer desta investigação, evidenciaram que quando o aluno decide suas jogadas e assume a responsabilidade por elas, aprende a ser autônomo, aprende a aprender, desenvolve seu senso crítico, analisa seus erros, aprende a conviver, aceita a importância de seguir regras, aceita que é parte da vida ganhar e perder. O processo de aprendizagem que foi 
mobilizado pelo uso de jogos permitiu esclarecer as estratégias construídas pelos alunos para a resolução de problemas, pois evidenciou as hipóteses levantadas e os conceitos utilizados, o que pode colaborar para o esclarecimento de alguns conteúdos e para a superação de concepções equivocadas.

No atual momento histórico em que a escola necessita reformular seu papel, de maneira a adaptar-se às mudanças sociais e tecnológicas e às necessidades de adequação da educação para o século XXI, a utilização de jogos pode provocar uma mudança positiva na rotina escolar, superando a aprendizagem mecânica da matemática e colaborando para resolver graves problemas pedagógicos como a indisciplina, a apatia e a exclusão. Jogando em sala de aula, o aluno aprende a fazer escolhas e a aceitar as consequências destas, tornando-se um ser mais completo e capaz de produzir conhecimentos e estratégias, e não simplesmente de apenas reproduzir o que lhe é fornecido.

Educar é sempre um desafio, e os profissionais da educação devem estar dispostos a aprender diariamente: é na prática de sala de aula que o conhecimento é construído, portanto o ambiente da sala de aula deve ser o mais estimulante possível para a busca pelo saber. A experiência com jogos em sala de aula ajuda a compreender o educando de modo mais completo, oferecendo oportunidades de interação professor-aluno e alunoaluno e colaborando para desenvolver o educando, assegurando-lhe a formação necessária para o exercício da cidadania e fornecendo-lhe os meios para progredir no trabalho e nos estudos. 


\section{Referências}

AUSUBEL, David Paul., NOVAK, Joseph e HANESIAN, Helen. Psicologia educacional. Rio de Janeiro: Interamericana, 1980.

BORIN, Júlia. Jogos e resolução de problemas: uma estratégia para as aulas de matemática. São Paulo: IME-USP, 1996.

BRASIL. Parâmetros Curriculares Nacionais: Matemática. Brasília, DF: MEC, 1997.

BRENELLI, Rosely Palermo. O jogo como espaço para pensar. Campinas: Papirus, 1996.

FREIRE, Paulo. Pedagogia da autonomia: saberes necessários à prática educativa. Rio de Janeiro: Paz e Terra, 1997.

GRANDO, Beleni Saléte. Jogos e culturas indígenas: possibilidades para a educação intercultural na escola. Cuiabá: EdUFMT, 2010.

GRANDO, Regina Célia. O conhecimento matemático e o uso de jogos na sala de aula. Tese Universidade de Campinas, Doutorado em Educação, Campinas, 2000.

KAMII, Constance e DEVRIES, Rheta. Jogos em grupo na educação infantil: implicações na teoria de Piaget. São Paulo: Trajetória Cultural, 1991.

KISHIMOTO, Tizuko Morchida. Jogo, brinquedo, brincadeira e a educação. São Paulo: Cortez, 1996.

MACEDO, Lino; PETTY, Ana Lucia Sicoli; PASSOS, Norimar Christe. Aprendendo com jogos e situações-problemas. Porto Alegre: Artmed, 2000.

MARCO, Fabiana Fiorezi. Estudo dos processos de resolução de problemas mediante a construção de jogos computacionais de matemática no ensino fundamental. Dissertação Universidade de Campinas, Mestrado em Educação Campinas, 2004.

MOURA, Manoel Oriosvaldo de. A séria busca no jogo: do lúdico na matemática. A Educação Matemática em Revista, SBEM, ano 2, n. 3, p.17-24, 1994.

NOVELLO, Mário. Os jogos da natureza. Rio de Janeiro: Elsevier, 2005.

PIAGET, Jean. A formação do símbolo na criança: imitação, jogo e sonho, imagem e representação. Rio de Janeiro: Zahar, 1978. 
PINTO, Neusa Bertoni. O erro como estratégia didática. Campinas: Papirus, 2000.

SMOLE, Katia Cristina Stocco; DINIZ, Maria Ignez; PESSOA, Neide; ISHIHARA,Cristiane.

Cadernos de Mathema: jogos de matemática de $1^{\circ}$ a $3^{\circ}$ ano. Porto Alegre: Artmed, 2008.

ZASLAVSKY, Claudia. Jogos e atividades matemáticas do mundo inteiro. Porto Alegre: Artmed, 2000.

ZASLAVSKY, Claudia. Mais jogos e atividades matemáticas do mundo inteiro. Porto Alegre: Artmed, 2009. 


\section{Complementos}

\section{Anexo 1- Jogo da Onça e dos Cachorros}

Material: tabuleiro, 14 peças representando os cachorros (pedrinhas, tampinhas, feijões, etc) e uma peça diferente representando a onça.

Regras: $\mathrm{O}$ jogo deve ter dois jogadores sendo que um deles é a onça, enquanto o outro representa os cachorros. Os adversários jogam alternadamente. $\mathrm{O}$ jogador, que utiliza a peça que representa a onça, tem o objetivo de capturar as peças (cachorros) adversárias capturando-as (comendo os cachorros), assim como num jogo de Damas. O jogador que utiliza as peças que representam os cachorros, para ganhar o jogo, precisa encurralar a onça de forma que ela não tenha movimento possível na sua vez de jogar. A onça vence $o$ jogo se comer 4 cachorros e os cachorros vencem se encurralarem a onça.

Tabuleiro do jogo da onça e dos cachorros:

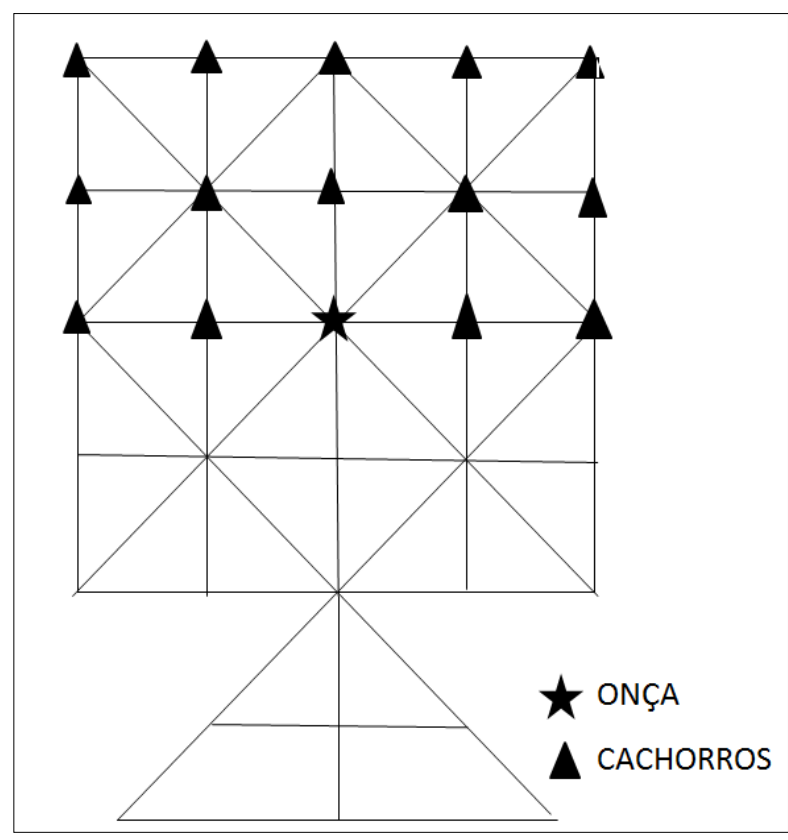




\section{Anexo 2- Jogo Contig}

Material: Tabuleiro, três dados e dois tipos diferentes de peças (feijões, tampinhas, pedrinhas, etc) para os dois jogadores colocarem nas casas do tabuleiro.

\section{As regras do jogo:}

1 - Os dois adversários jogam alternadamente. Na sua vez, cada jogador joga os três dados e constrói uma sentença numérica usando os números indicados pelos dados e duas operações aritméticas. Por exemplo, com os números 2, 3 e 4, o jogador poderá construir $(2+3) \times 4=20$. 0 jogador, neste caso, cobriria o espaço marcado 20 com uma ficha de sua cor. Só é permitido utilizar as quatro operações básicas.

2 - Se um jogador passar sua jogada, por acreditar que não é possível fazer uma sentença numérica com os valores sorteados nos dados, o adversário terá uma opção a tomar: se achar que seria possível fazer uma sentença com os dados jogados pelo colega, poderá fazer a sentença numérica antes de fazer sua própria jogada. Ele ganhará, neste caso, o dobro dos números de pontos, e em seguida poderá fazer sua própria jogada.

3 - O jogo termina quando um jogador conseguir atingir o número de pontos definidos no início do jogo (30 ou 40, por exemplo) ou colocar 5 fichas de mesma cor em linha reta sem nenhuma ficha do adversário intervindo: essa linha poderá ser horizontal, vertical ou diagonal.

\section{Contagem dos pontos:}

Um ponto é ganho por colocar uma ficha num espaço desocupado que seja vizinho a um espaço com uma ficha de qualquer cor (horizontalmente, verticalmente ou diagonalmente). Colocando-se um marcador num espaço vizinho a mais de um espaço ocupado, mais pontos poderão ser obtidos. A cor das fichas nos espaços ocupados não faz diferença. Os pontos obtidos numa jogada são somados para o jogador. Observe o exemplo a seguir: suponhamos que uma partida tenha sido iniciada pelo jogador $A$ que possuí a ficha vermelha colocada na casa 37 (por exemplo, ele pode ter escolhido a casa 37 , se obteve nos dados os valores 6,6 e 1 , pois $6 \times 6+1=37$ ). Ao jogar seus dados, 0 
segundo jogador, que possuí a ficha azul, tira 3,3 e 4 e faz os seguintes cálculos $3 \times 3 \times 4=$ 36. Isso the possibilita conseguir um ponto. O jogador $A$, jogando os dados, tira os números 5, 6 e 1 e faz 5+1+6 = 12. Colocando sua ficha vermelha na casa 12, este consegue marcar dois pontos.

\section{Tabuleiro do jogo Contig:}

\begin{tabular}{|c|c|c|c|c|c|c|c|}
\hline 0 & 1 & 2 & 3 & 4 & 5 & 6 & 7 \\
\hline 27 & 28 & 29 & 30 & 31 & 32 & 33 & 8 \\
\hline 26 & 54 & 55 & 60 & 64 & 66 & 34 & 9 \\
\hline 25 & 50 & 120 & 125 & 144 & 72 & 35 & 10 \\
\hline 24 & 48 & 108 & 180 & 150 & 75 & 36 & 11 \\
\hline 23 & 45 & 100 & 96 & 90 & 80 & 37 & 12 \\
\hline 22 & 44 & 42 & 41 & 40 & 39 & 38 & 13 \\
\hline 21 & 20 & 19 & 18 & 17 & 16 & 15 & 14 \\
\hline \hline
\end{tabular}




\section{Anexo 3 - Problema Proposto para o Jogo Contig}

Observe o tabuleiro do jogo Contig abaixo. Você é o jogador com o marcador vez de jogar. Qual será o melhor número para sua jogada? Justifique sua escolha. Escreva na linguagem matemática as possíveis operações com os possíveis valores dos três dados que resultariam no número que você escolheu como melhor jogada.

\begin{tabular}{|c|c|c|c|c|c|c|c|}
\hline 0 & 1 & $2 \star$ & 3 & 4 & 5 & 6 & 7 \\
\hline 27 & 28 & 29 & $30 \star$ & 31 & 32 & 33 & 8 \\
\hline 26 & 54 & 55 & 60 & 64 & 66 & 34 & 9 \\
\hline 25 & 50 & 120 & 125 & 144 & 72 & 35 & 10 \\
\hline 24 & 48 & 108 & 180 & 150 & 75 & 36 & ${ }^{11}$ \\
\hline 23 & 45 & 100 & 96 & 90 & 80 & 37 & 12 \\
\hline 22 & 44 & 42 & 41 & 40 & 39 & 38 & 13 \\
\hline 21 & 20 & 19 & 18 & 17 & 16 & 15 & 14 \\
\hline
\end{tabular}

Recebido em: 27/06/2013 Aprovado em: 19/02/2014

Universidade do Estado de Santa Catarina - UDESC Programa de Pós-Graduação em Educação - PPGE Revista Linhas Volume 15 - Número 28 - Ano 2014 revistalinhas@gmail.com 